\title{
Downregulation of miRNA-328 promotes the angiogenesis of HUVECs by regulating the PIM1 and AKT/mTOR signaling pathway under high glucose and low serum condition
}

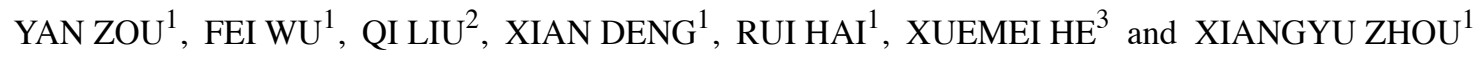 \\ ${ }^{1}$ Department of Thyroid Surgery, The Affiliated Hospital of Southwest Medical University, Luzhou, Sichuan 646000; \\ ${ }^{2}$ Department of Pediatrics, Nanchong Central Hospital, Nanchong, Sichuan $637000 ;{ }^{3}$ Medical Research Center, \\ The Affiliated Hospital of Southwest Medical University, Luzhou, Sichuan 646000, P.R. China
}

Received August 29, 2019; Accepted April 8, 2020

DOI: $10.3892 / \mathrm{mmr} .2020 .11141$

\begin{abstract}
Vascular complications are the primary reason for disability and mortality associated with diabetes mellitus (DM), and numerous microRNAs (miRNAs/miRs) are involved in the process, such as miR-122, miR-24 and miR-423. It has been reported that miR-328 regulates DM and cardiovascular disease; however, the role and mechanism of action underlying miR-328 in HUVECs is not completely understood. The present study aimed to investigate the role and mechanism of action underlying the effects of miR-328 on the functions of HUVECs. To simulate hyperglycemia combined with ischemia-induced tissue starvation, HUVECs were cultured in endothelial cell medium with $25 \mathrm{mmol} / 1$ D-glucose and 2\% FBS for $24 \mathrm{~h}$ [high glucose (HG) $+2 \%$ FBS group]. HUVEC miR-328 expression levels were detected by reverse transcription-quantitative PCR. Cell migration, cytotoxicity and tube-like structure formation were analyzed using wound healing, Cell Counting Kit- 8 and tube formation assays, respectively. Following transfection with miR-328 inhibitor, miR-328 expression was downregulated in HUVECs. Protein expression levels were determined by western blotting. Compared with the control group, the migration and tube-like structure formation of HUVECs were decreased, and cell cytotoxicity was increased in the $\mathrm{HG}+2 \% \mathrm{FBS}$ group. The protein expression levels of vascular endothelial growth factor were also decreased, and the expression levels of miRNA-328 in the $\mathrm{HG}+2 \%$ FBS group were increased compared with the control group. However, miRNA-328 downregulation reversed the aforementioned effects. Further experiments indicated that the AKT signaling pathway was inhibited in the $\mathrm{HG}+$
\end{abstract}

Correspondence to: Professor Xiangyu Zhou, Department of Thyroid Surgery, The Affiliated Hospital of Southwest Medical University, 25 Taiping Street, Jiangyang, Luzhou, Sichuan 646000, P.R. China

E-mail: xiangyuzhou971@vip.126.com

Key words: microRNA-328, diabetes mellitus, HUVECs, angiogenesis, vascular endothelial growth factor
2\% FBS group; however, miR-328 downregulation activated the AKT/mTOR signaling pathway, which was blocked by the AKT signaling pathway inhibitor, perifosine. Gene prediction and western blotting demonstrated that miR-328 displayed a regulatory role via Pim-1 proto-oncogene, serine/threonine kinase (PIM1). In conclusion, miR-328 expression was upregulated and angiogenesis was inhibited when HUVECs were subjected to high glucose and low serum conditions. miR-328 downregulation enhanced angiogenesis by increasing PIM1 expression and activating the AKT/mTOR signaling pathway in HUVECs under high glucose and low serum conditions.

\section{Introduction}

Diabetes mellitus (DM) characterized by hyperglycemia, is the most common metabolic disease worldwide and has become a global threat to human health (1). Patients with DM suffer from endothelial dysfunction and vascular damage due to a variety of harmful stimuli, including hyperglycemia, hyperlipidemia, oxidative stress and inflammation, which eventually lead to a series of diabetic vascular complications, including peripheral artery disease (PAD) (2). Severe hypoperfusion of blood flow for an extended period in patients with PAD leads to ischemic foot ulceration and the development of gangrene, which is one of the primary causes of foot amputation (3), and for a number of patients, this stage may be the only outcome. Although controlling and managing vascular risk factors can effectively improve the treatment of DM, the incidence, disability and mortality rates of diabetic peripheral vascular disease remain high (4). The mechanisms underlying angiogenesis repair following ischemia and endothelial cell function impairment during DM are not completely understood. At present, it has been suggested that promoting ischemic tissue angiogenesis may serve as a therapeutic strategy for PAD $(5,6)$.

The primary cause of delayed wound healing in patients with diabetes is impaired angiogenesis (7). Angiogenesis refers to the migration and proliferation of vascular endothelial cells based on original capillaries and/or venues and the formation of new capillaries from pre-existing vessels in the form of budding or non-budding (8). Angiogenesis serves an important role in promoting the recovery of diabetic vascular compli- 
cations (9) and is regulated by angiogenic factors, involving endothelial cell proliferation, migration and tube-like structure formation (10). Previous studies have demonstrated that angiogenesis can be regulated by microRNAs (miRNAs) and that vascular-specific miRNAs are key regulators of angiogenesis (11). miRNAs are endogenous non-coding RNAs that are $\sim 22$ nucleotides in length. miRNAs regulate endothelial cell migration, proliferation and tube-like structure formation, as well as the expression of angiogenesis-related factors, ultimately affecting angiogenesis (12). miRNAs are able to promote and inhibit angiogenesis; miRNA-126, miRNA-378 and miRNA-132 promote angiogenesis, whereas miRNA-195, miRNA-221 and miR-192 inhibit angiogenesis (11). Therefore, there is a theoretical basis for the use of miRNAs as a biological therapy for treating diabetic vascular complications. High glucose (HG) levels can upregulate the expression levels of miRNA-328 to induce HUVEC epithelial-mesenchymal transition, and the mechanism of action is related to the mitogen-activated protein kinase kinase-1/2-ERK1/2 signaling pathway (13). Previous studies have indicated that miR-328 antagonists can improve erectile dysfunction in a rat model of diabetes by regulating the expression levels of cGMP and advanced glycation end products (14), and miR-328 can modulate glucose uptake and metabolism related to diabetic retinopathy $(15,16)$. However, the role and mechanism of action underlying miR-328 during HUVEC angiogenesis under hyperglycemic and ischemic conditions is not completely understood.

In the present study, to simulate hyperglycemia combined with ischemia-induced tissue starvation, HUVECs were cultured in endothelial cell medium (ECM) with $25 \mathrm{mmol} / \mathrm{l}$ D-glucose and 2\% FBS for $24 \mathrm{~h}$ (HG $+2 \%$ FBS group). Subsequently, cell functions related to HUVEC angiogenesis were investigated, including migration, cytotoxicity and tube-like structure formation. The expression levels of miRNA-328 and vascular endothelial growth factor (VEGF), a marker of angiogenesis, were detected. Subsequently, the expression level of miR-328 was regulated in the HUVEC model of diabetic vascular ischemia and subsequently, endothelial cell functions and VEGF expression levels were observed. The mechanism of action underlying miR-328-mediated angiogenesis regulation in the HUVEC model of diabetic vascular ischemia was explored.

\section{Materials and methods}

Cell culture and treatment. HUVECs (ScienCell Research Laboratories, Inc.) were grown in complete ECM (SciencCell Research Laboratories, Inc.) containing 5\% FBS (SciencCell Research Laboratories, Inc.), $1 \%$ EC growth factors (ECGS; SciencCell Research Laboratories, Inc.) and $1 \%$ penicillin and streptomycin at $37^{\circ} \mathrm{C}$ in an atmosphere containing $5 \% \mathrm{CO}_{2}$. Cells at passage 3-5 in the logarithmic growth phase were used for subsequent experiments. Type $2 \mathrm{DM}$ combined with arteriosclerosis obliterans is a complex disease, and in vitro, several stimulating factors, such as HG, low growth factors, advanced glycation end products, oxidized LDL and serum starvation, combined with hypoxia have been used to induce cell models (17-19). Therefore, HUVECs were cultured for $24 \mathrm{~h}$ at $37^{\circ} \mathrm{C}$ with ECM containing $25 \mathrm{mmol} / \mathrm{l} \mathrm{D}$-glucose to mimic HG, and 2\% FBS and low growth factor levels to mimic ischemia-induced tissue starvation ( $\mathrm{HG}+2 \%$ FBS group). HUVECs were exposed to Perifosine $(1 \mu \mathrm{M}$; cat. no. HY-50909; MedChemExpress) for $24 \mathrm{~h}$ at $37^{\circ} \mathrm{C}$ in an atmosphere containing $5 \% \mathrm{CO}_{2}$, then downregulation of miR-328 was performed and the changes in protein and cell function were measured.

Wound healing assay. HUVECs were seeded $\left(5 \times 10^{5}\right.$ cells/well) into 6-well plates. At 90\% confluence, a single scratch was made in the cell monolayer using a sterile $200 \mu \mathrm{l}$ pipette tip. Subsequently, the cells were cultured for $24 \mathrm{~h}$ at $37^{\circ} \mathrm{C}$ in an atmosphere containing $5 \% \mathrm{CO}_{2}$. The control group was cultured in ECM containing $2 \%$ FBS, whereas the $\mathrm{HG}+2 \%$ FBS group was cultured in ECM containing HG and $2 \%$ FBS. Cells were observed in six random fields of view at 0,6 and $24 \mathrm{~h}$ using an inverted light microscope (magnification, $\mathrm{x} 40$ ). ImageJ version 1.49 software (National Institutes of Health) was used for image analysis and quantification.

Cell Counting Kit-8(CCK-8) assays. HUVEC cytotoxicity was determined using the CCK- 8 assay, according to the manufacturer's instructions. Cells were seeded $\left(1 \times 10^{3}\right.$ cells/well) into 96-well flat-bottomed plates with 5 replicates in each group. Following treatment with $25 \mathrm{mmol} / \mathrm{l} \mathrm{D}$-glucose and $2 \%$ FBS for $24 \mathrm{~h}$, or transfection with miR-328 inhibitor (IN328) and treatment with $25 \mathrm{mmol} / \mathrm{l} \mathrm{D}$-glucose and $2 \%$ FBS for $24 \mathrm{~h}$, the cells were washed twice with PBS. Subsequently, CCK-8 reagent (10 $\mu \mathrm{l}$; Beyotime Institute of Biotechnology) was added to each well and incubated at $37^{\circ} \mathrm{C}$ for $2 \mathrm{~h}$ in the dark. The optical density (OD) values of each well were measured at a wavelength of $450 \mathrm{~nm}$ using a microplate reader (Bio-Rad Laboratories, Inc.).

Tube formation assay. To assess tube formation, pre-cooled 48-well plates were coated with Matrigel ${ }^{\boxplus}(30 \mu \mathrm{l})$ at $37^{\circ} \mathrm{C}$ for $30 \mathrm{~min}$. HUVECs were seeded $\left(1.0 \times 10^{5} \mathrm{cells} / \mathrm{ml}\right)$ onto the Matrigel ${ }^{\oplus}$-coated plates at $37^{\circ} \mathrm{C}$ in an atmosphere containing $5 \% \mathrm{CO}_{2}$ for $16 \mathrm{~h}$. Tube-like structure formation was observed using an inverted light microscope (magnification, x100; Olympus Corporation).

RNA extraction and reverse transcription-quantitative $P C R(R T-q P C R)$. Total RNA was extracted using TRIzol ${ }^{\circledR}$ (Invitrogen; Thermo Fisher Scientific, Inc.). Total RNA (500 ng) was reverse transcribed to cDNA using a miRcute Plus miRNA First-Strand cDNA kit (Tiangen Biotech Co., Ltd.), according to the manufacturer's instructions. Subsequently, qPCR was performed using the miRcute Plus miRNA qPCR Detection kit (Tiangen Biotech Co., Ltd.) and a StepOne Plus PCR system (Applied Biosystems; Thermo Fisher Scientific, Inc.), according to the manufacturer's protocol. The following thermocycling conditions were used for the qPCR: Initial denaturation at $95^{\circ} \mathrm{C}$ for $15 \mathrm{~min}$; followed by 40 cycles of denaturation at $94^{\circ} \mathrm{C}$ for $15 \mathrm{sec}$, annealing at $55^{\circ} \mathrm{C}$ for $30 \mathrm{sec}$ and extension at $70^{\circ} \mathrm{C}$ for $30 \mathrm{sec}$. The primers for hsa-miR-328 and U6 were purchased from Guangzhou RiboBio Co., Ltd. miRNA expression levels were quantified using the $2^{-\Delta \Delta \mathrm{Cq}}$ method and normalized to the internal reference gene U6 (20). RT-qPCR was performed in triplicate. 
Transfections. IN328 (100 nmol/l; Guangzhou RiboBio Co., Ltd.) or its negative control (NC; 100 nmol/l; Guangzhou RiboBio Co., Ltd.) were used in the present study. Following transfection at $37^{\circ} \mathrm{C}$ in an atmosphere containing $5 \% \mathrm{CO}_{2}$ for $12 \mathrm{~h}$, the culture medium was replaced with fresh medium. After $24 \mathrm{~h}, \mathrm{HUVECs}$ were exposed to $\mathrm{HG}$ and $2 \% \mathrm{FBS}$ at $37^{\circ} \mathrm{C}$ in an atmosphere containing $5 \% \mathrm{CO}_{2}$ and subsequently, wound healing, CCK-8, tube formation and western blot assays were performed.

Western blotting. Cells were lysed using RIPA buffer (Beyotime Institute of Biotechnology). Total protein was quantified using a bicinchoninic acid assay kit (Thermo Fisher Scientific, Inc.). Subsequently, proteins (30 $\mu \mathrm{g})$ were separated via $10 \%$ SDS-PAGE and transferred onto PVDF membranes. Following blocking with non-fat milk for $2 \mathrm{~h}$ at room temperature (Beyotime Institute of Biotechnology), the membranes were incubated at $4^{\circ} \mathrm{C}$ overnight with the following primary antibodies: Anti-VEGF (1:1,000; cat. no. AV202; Beyotime Institute of Biotechnology), anti-phosphorylated (p)-AKT (Ser-473; 1:1,000; cat. no. ab81823; Abcam), anti-AKT (1:1,000; cat. no. ab18785; Abcam), anti-p-ERK (1:1,000; cat. no. ab47339; Abcam), anti-ERK (1:1,000; cat. no. ab17942; Abcam), anti-p-JNK (1:1,000; cat. no. ab124956; Abcam), anti-JNK (1:1,000; cat. no. ab208035; Abcam), anti-mTOR (1:1,000, cat. no. AM832; Beyotime Institute of Biotechnology), anti-p-mTOR (1:1,000, cat. no. 5536; Cell Signaling Technologies), anti-PIM1 (1:1,000; cat. no. 54523; Cell Signaling Technologies), anti-GAPDH (1:1,000; cat. no.97166; Cell Signaling Technologies), anti-actin (1:1,000; cat. no. 3700; Cell Signaling Technologies) and anti- $\beta$-tubulin (1:1,000; cat. no.2146; Cell Signaling Technologies). Following primary incubation, the membranes were incubated with horseradish peroxidase-conjugated secondary antibodies for $1 \mathrm{~h}$ at room temperature: Anti rabbit $\operatorname{IgG}(1: 2,000$; cat. no. A0208) and anti mouse IgG (1:2,000; cat. no. A0216) were purchased from Beyotime Institute of Biotechnology. Protein bands were visualized by enhanced chemiluminescence detection reagent (Bio Rad Laboratories, Inc.), and blots were semi quantified by densitometric analysis using Quantity One v4.6.2 software (Bio Rad Laboratories, Inc.). GAPDH, actin and $\beta$-tubulin were used as the loading controls.

Predict target gene. Firstly, the target gene of miR-328 was predicted in the miRWalk2.0 database (http://zmf.umm. uni-heidelberg.de/apps/zmf/mirwalk/), and the intersection of target genes in TargetScanHuman 7.1 (http://www.targetscan. org/vert_71/), miRDB (http://mirdb.org/) and miRWalk2.0 database was selected as the predicted target gene. Then, the target genes and signal pathways related to angiogenesis were found in the Database for Annotation, Visualization, and Integrated Discovery (DAVID; https://david.ncifcrf.gov/). Then, the target genes for promoting angiogenesis were found by reference (21).

Statistical analysis. All experiments were performed in at least triplicate. Data are presented as the mean \pm standard deviation (SD). One-way ANOVA followed by the Student-Newman-Keuls post hoc test was used to analyze differences among multiple groups. An unpaired Student's t-test was used to analyze differences between two groups. Statistical analyses were performed using SPSS software (v19.0; IBM Corp.). $\mathrm{P}<0.05$ was considered to indicate a statistically significant difference.

\section{Results}

HUVEC angiogenesis is inhibited under HG and low serum conditions. Alterations to HUVEC angiogenesis, cell function and VEGF protein expression levels were observed following culture with $\mathrm{HG}$ and low serum for $24 \mathrm{~h}$. In terms of cell function, cell migration, cytotoxicity and tube-like structure formation were evaluated. Cells were divided into two groups: i) Control group; and ii) $\mathrm{HG}+2 \%$ FBS group. Wound healing assays were performed to measure HUVEC migration (Fig. 1A). Compared with the control group, the $6 \mathrm{~h}$ wound healing rate of the $\mathrm{HG}+2 \%$ FBS group was decreased $(\mathrm{P}<0.01)$, which suggested that $\mathrm{HG}$ and low serum conditions inhibited the migration of endothelial cells. The CCK-8 assay was used to measure HUVEC cytotoxicity (Fig. 1B). Compared with the control group, the OD value of the $\mathrm{HG}+2 \%$ FBS group was decreased $(\mathrm{P}<0.01)$, which indicated that $\mathrm{HG}$ and low serum conditions increased the cytotoxicity of endothelial cells. Tube formation assays were performed to detect the tube-like structure formation of HUVECs (Fig. 1C). Compared with the control group, the total length of the tube-like structures was decreased in the $\mathrm{HG}+2 \%$ FBS group $(\mathrm{P}<0.01)$, which indicated that $\mathrm{HG}$ and low serum conditions inhibited the tube-like structure formation of endothelial cells. Furthermore, western blotting was performed to detect VEGF protein expression levels (Fig. 1D). Compared with the control group, the relative expression levels of VEGF in the $\mathrm{HG}+2 \%$ FBS group were decreased $(\mathrm{P}<0.01)$, which indicated that $\mathrm{HG}$ and low serum conditions inhibited the angiogenesis of endothelial cells at the protein level. Collectively, the results suggested that endothelial cell angiogenesis was inhibited under HG and low serum conditions.

miR-328 expression is increased and the AKT signaling pathway is suppressed in HUVECs under HG and low serum conditions. To clarify the effect of $\mathrm{HG}$ and low serum conditions, miR-328 expression levels and the ratios of p-AKT/AKT, p-ERK/ERK and p-JNK/JNK were determined in HUVECs following treatment with $\mathrm{HG}$ and low serum for 24 h. miR-328 expression levels were significantly increased in the $\mathrm{HG}+2 \%$ FBS group compared with the control group (Fig. 2A). Moreover, the ratio of p-AKT/AKT was significantly decreased in the $\mathrm{HG}+2 \%$ FBS group compared with the control group. However, the ratios of $\mathrm{p}-\mathrm{ERK} / \mathrm{ERK}$ and p-JNK/JNK were not significantly different between the control group and the $\mathrm{HG}+2 \%$ FBS group (Fig. 2B). The results indicated that the AKT signaling pathway was associated with miR-328-mediated regulation of cell function, but the ERK and JNK signaling pathways are not associated with miR-328-mediated effects. Based on the finding that only the AKT signaling pathway was altered in HUVECs following treatment with $\mathrm{HG}$ and $2 \%$ FBS, only the AKT signaling pathway was investigated in subsequent experiments. The results suggested that the inhibition of endothelial cell angiogenesis by HG and low serum conditions may be related to miR-328 and the AKT signaling pathway. 
A

$\mathrm{CON}$
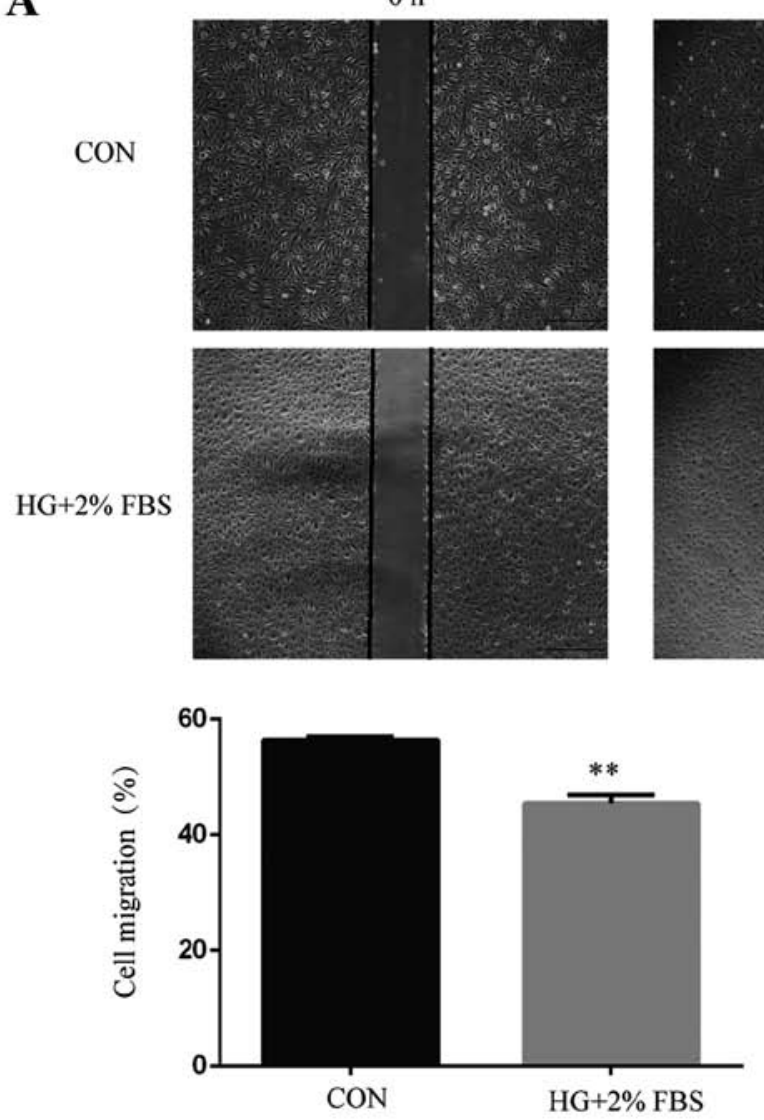

C

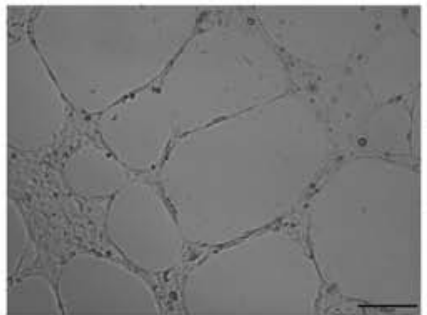

CON

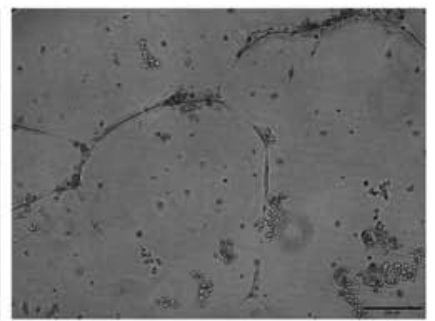

$\mathrm{HG}+2 \%$ FBS
$6 \mathrm{~h}$
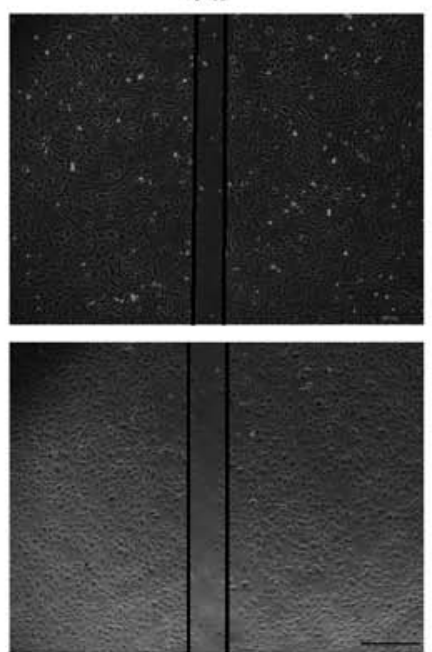

$24 \mathrm{~h}$
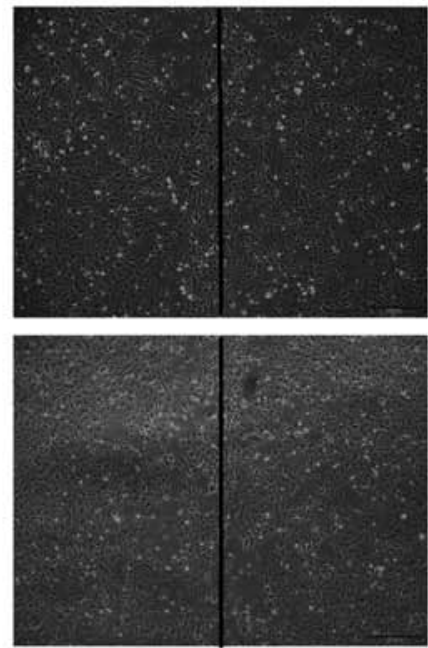

B
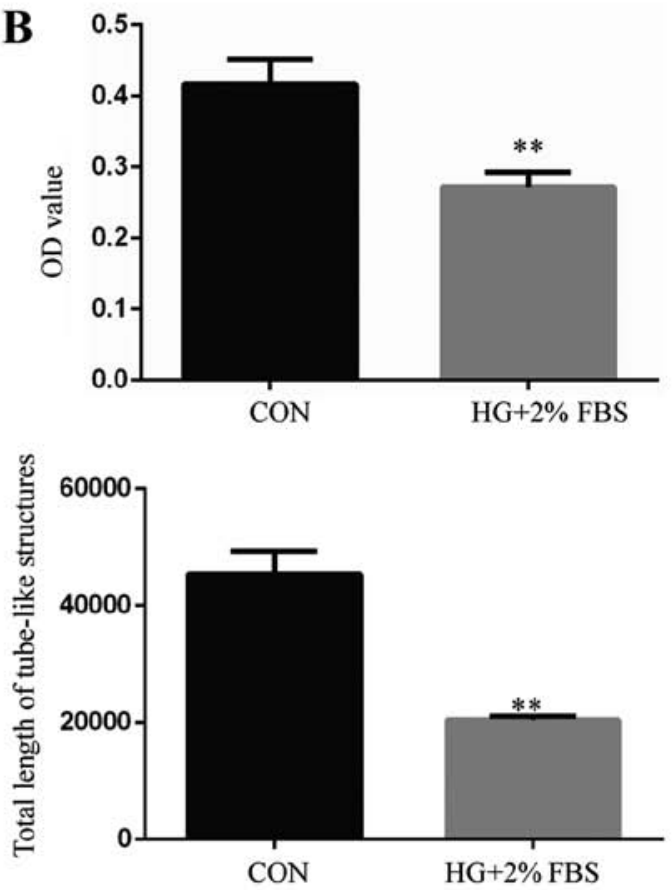

D
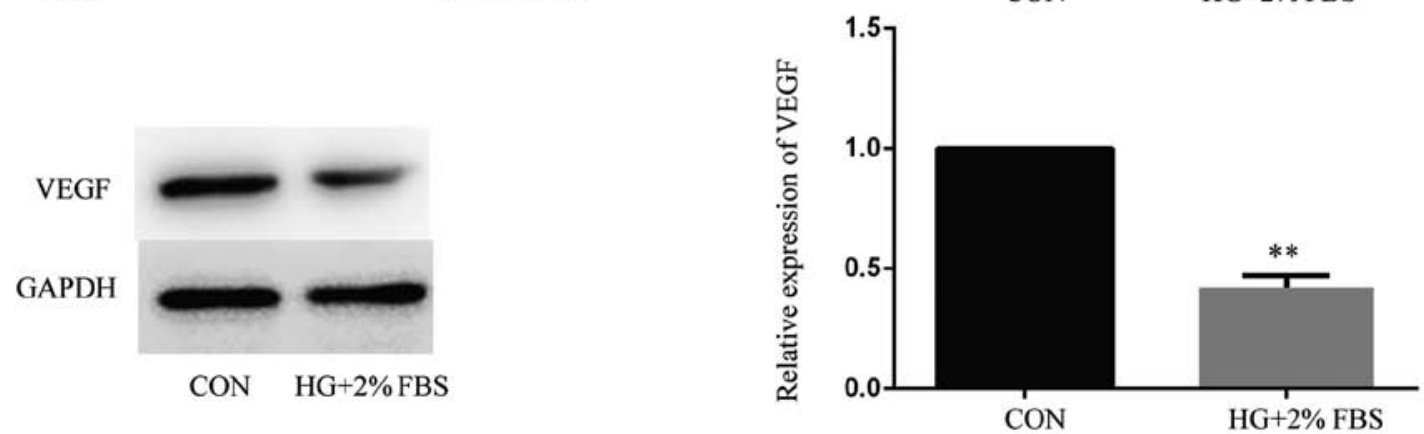

Figure 1. HUVEC angiogenesis is inhibited under HG and low serum conditions. (A) HUVEC migration was determined using wound healing assays (magnification, x40). The data presented in the graph in Fig. 1A are from the $6 \mathrm{~h}$ time point. Scale bar, $500 \mu \mathrm{m}$. (B) HUVEC cytotoxicity was detected using the Cell Counting Kit-8 assay. (C) HUVEC tube-like structure formation was detected using tube formation assays (magnification, $\mathrm{x} 100$ ). Scale bar, $200 \mu \mathrm{m}$. (D) The expression levels of VEGF were detected by western blotting. ${ }^{* *} \mathrm{P}<0.01$ vs. CON. HG, high glucose; VEGF, vascular endothelial growth factor; CON, control; OD, optical density.

Downregulation of miR-328 promotes HUVEC angiogenesis under $H G$ and low serum conditions. To investigate the angiogenesis function of miR-328 under HG and low serum conditions, HUVECs were divided into the NC and IN328 groups. Transfection efficiency of IN328 was detected using RT-qPCR. Compared with the NC group, the expression of miR-328 in the IN328 group was significantly lower, which indicated that the transfection was successful (Fig. S1). 
A
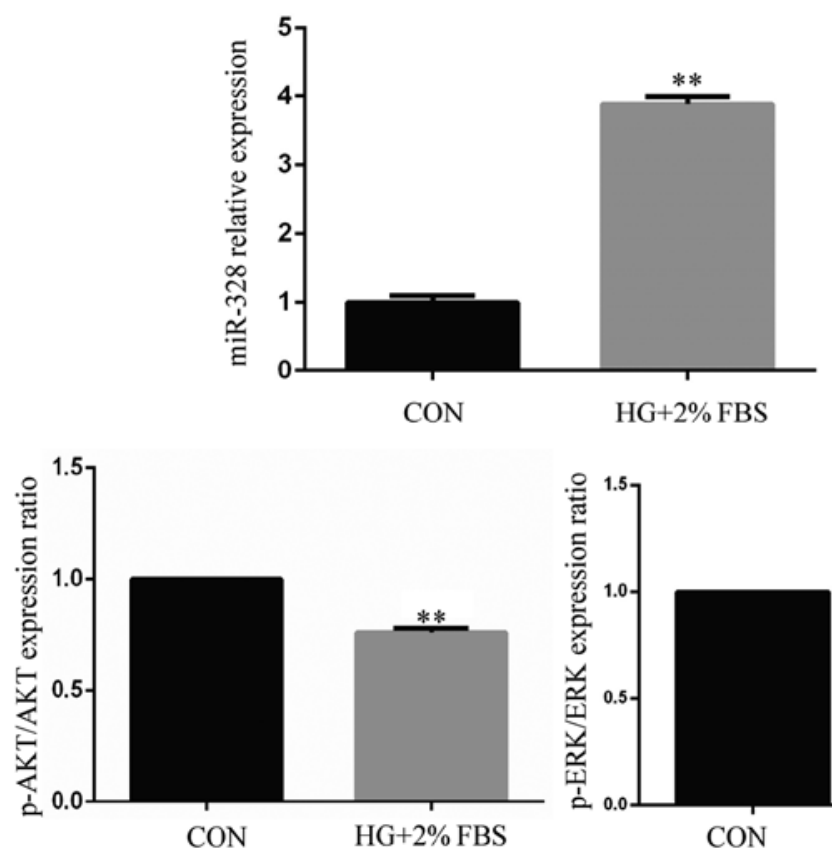

B

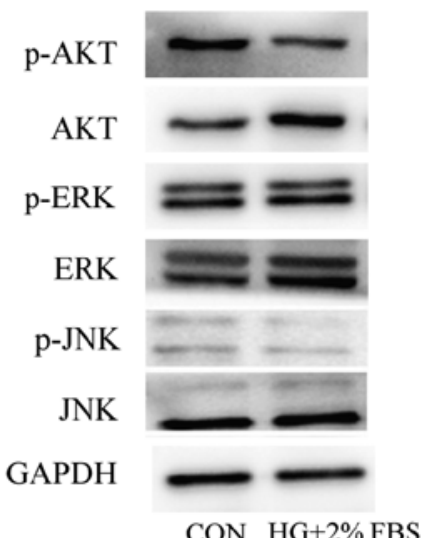

Figure 2. HG and low serum conditions promote the expression of miR-328 and inhibit activation of the AKT signaling pathway in HUVECs. (A) miR-328 expression levels in the control group and the $\mathrm{HG}+2 \%$ FBS group. (B) Protein expression levels were determined by western blotting and the ratios of p-AKT/AKT, p-ERK/ERK and p-JNK/JNK were semi-quantified. ${ }^{* *} \mathrm{P}<0.01$ vs. CON. HG, high glucose; miR, microRNA; p, phosphorylated; CON, control.

Subsequently, angiogenesis and VEGF protein expression levels were investigated. The wound healing assay was performed to detect the migratory ability of HUVECs. Compared with the NC group, the $6 \mathrm{~h}$ wound healing rate of the IN328 group was increased $(\mathrm{P}<0.01)$, which indicated that downregulation of miR-328 promoted endothelial cell migration (Fig. 3A). Compared with the NC group, the OD value of the IN328 group was increased $(\mathrm{P}<0.01)$, which demonstrated that downregulation of miR-328 reduced cell cytotoxicity (Fig. 3B). Tube formation assays were performed to detect tube-like structure formation in HUVECs. Compared with the $\mathrm{NC}$ group, the total length of tube-like structures in the IN328 group was increased $(\mathrm{P}<0.01)$, which suggested that downregulation of miR-328 promoted tube-like structure formation in endothelial cells (Fig. 3C). Additionally, western blotting was performed to detect VEGF protein expression levels in HUVECs. Compared with the NC group, the relative expression levels of VEGF in the IN328 group were increased $(\mathrm{P}<0.01)$, which indicated that downregulation of miR-328 promoted endothelial cell angiogenesis at the protein level (Fig. 3D). The results suggested that endothelial cell angiogenesis was enhanced by downregulation of miR-328 under HG and low serum conditions.

Downregulation of miR-328 activates the AKT/mTOR signaling pathway in HUVECs under HG and low serum conditions. The aforementioned results indicated that HG and low serum conditions inhibited activation of the AKT signaling pathway in HUVECs. Moreover, it has been reported that the AKT/mTOR signaling pathway can regulate angiogenesis; therefore, alterations in the AKT/mTOR signaling pathway were investigated following downregulation of miR-328. Following miR-328 downregulation in HUVECs under HG and low serum conditions, inhibiting AKT phosphorylation with perifosine partially reversed IN328-mediated tube-like structure formation, which indicated that perifosine at least partially blocked IN328-mediated stimulation of HUVEC angiogenesis (Fig. 4A). Following downregulation of miR-328 in HUVECs under HG and low serum conditions, the ratios of p-AKT/AKT and p-mTOR/mTOR were significantly increased compared with the NC group, indicating that the AKT/mTOR signaling pathway was activated (Fig. 4B). By inhibiting AKT phosphorylation with perifosine in the IN328 group, the ratios of $\mathrm{p}-\mathrm{AKT} / \mathrm{AKT}$ and $\mathrm{p}-\mathrm{mTOR} / \mathrm{mTOR}$ were decreased, which indicated that perifosine blocked the AKT/mTOR signaling pathway (Fig. 4B). The results demonstrated that downregulation of miR-328 promoted HUVECs angiogenesis by activating the AKT/mTOR signaling pathway under HG and low serum conditions.

miR-328 may serve a regulatory role via PIM1. Based on the sequence of miR-328, possible binding targets of miR-328 were predicted by miRWalk2.0 and DAVID database. Subsequently, proangiogenesis-associated predicted targets were selected. PIM1, a gene that is associated with cell survival, was one of the predicted targets (Fig. 5A). To verify the prediction, IN328 and a NC were transfected into HUVECs under HG and low serum conditions. The western blotting results indicated that IN328 significantly increased PIM1 protein expression levels compared with the NC group (Fig. 5B). The results indicated that miR-328 regulated endothelial cell angiogenesis via PIM1 (Fig. 6). 
A

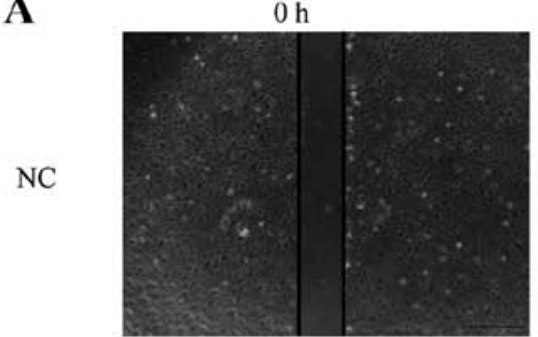

IN 328

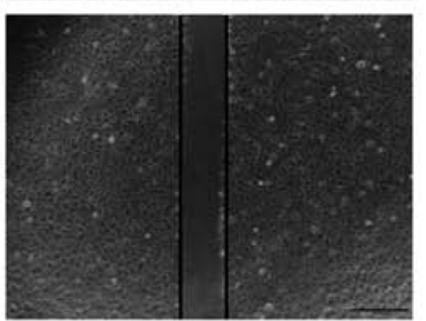

$6 \mathrm{~h}$
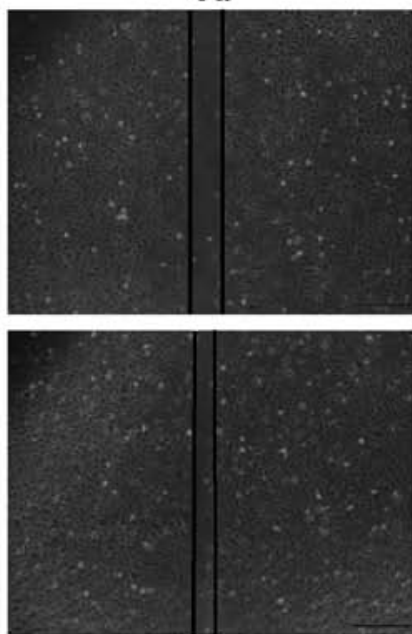

$24 \mathrm{~h}$
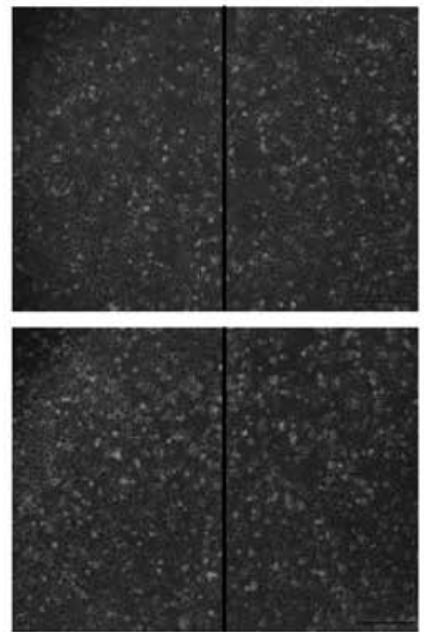

C
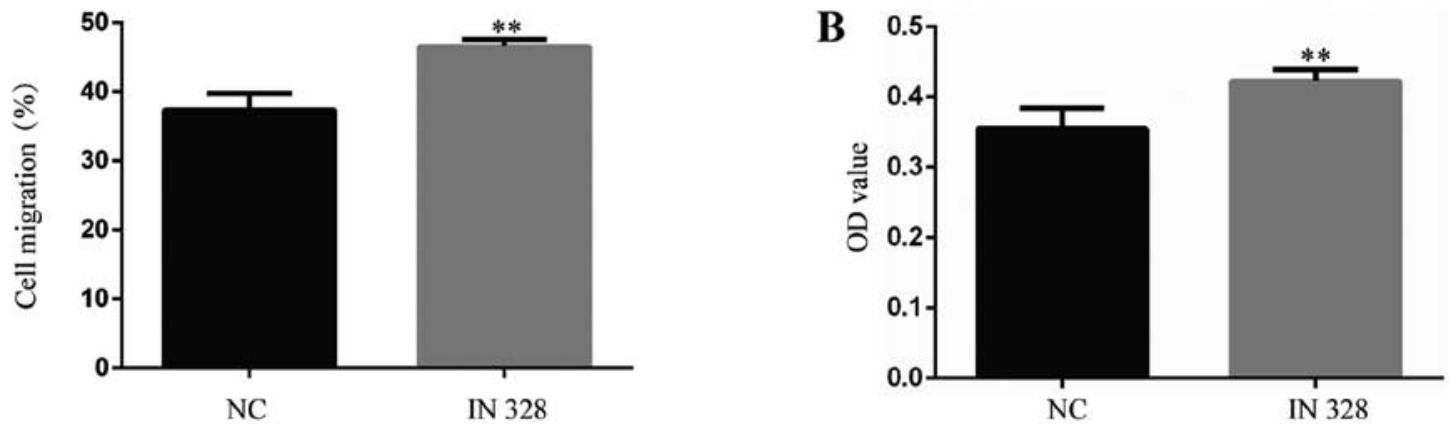

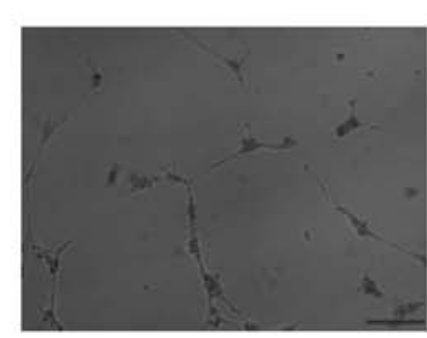

NC

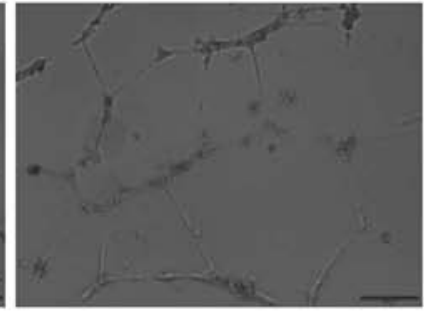

IN 328

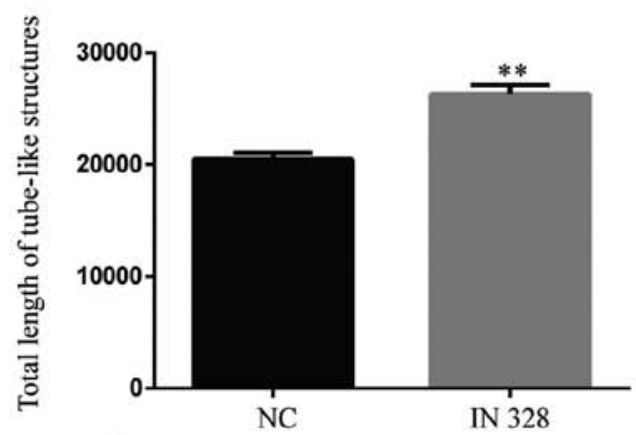

$\mathbf{D}$

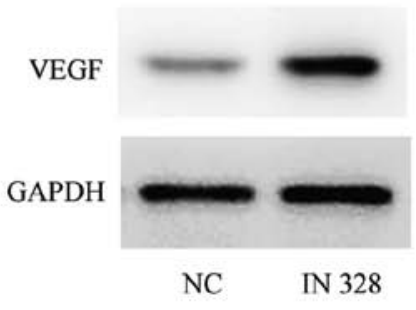

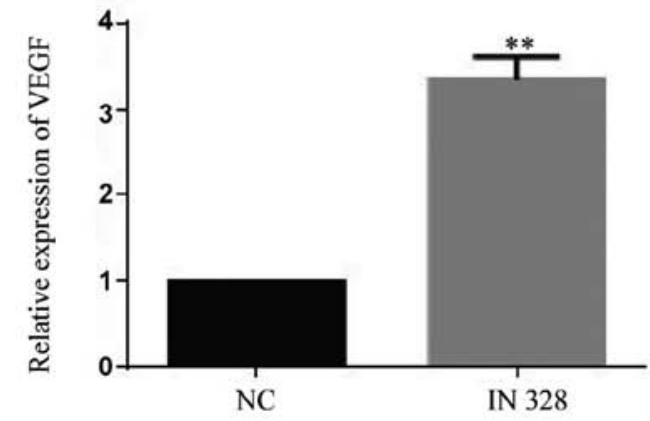

Figure 3. Downregulation of miR-328 promotes HUVECs angiogenesis under HG and low serum condition. (A) HUVEC migration was determined using wound healing assays (magnification, $\mathrm{x} 40$ ). The data presented in the graph are from the $6 \mathrm{~h}$ time point. Scale bar, $500 \mu \mathrm{m}$. (B) HUVEC cytotoxicity was determined using the Cell Counting Kit-8 assay. (C) The tube-like structure formation of HUVECs was detected using tube formation assays (magnification, x100). Scale bar, $200 \mu \mathrm{m}$. (D) VEGF protein expression levels in HUVECs were determined by western blotting. ${ }^{* *} \mathrm{P}<0.01 \mathrm{vs.} \mathrm{CON}$. miR, microRNA; HG, high glucose; VEGF, vascular endothelial growth factor; CON, control; IN328, miR-328 inhibitor; OD, optical density.

\section{Discussion}

Increasing evidence suggests that endothelial cell dysfunction contributes to the onset and progression of diabetes-related vascular complications (22); therefore, the role of miRNAs as regulatory factors during such processes have gained increasing attention. Although the effects of miR-328 have been studied extensively, the mechanism underlying miR-328 during HUVEC angiogenesis is not completely understood. In the present study, whether miR-328 expression levels were 
A

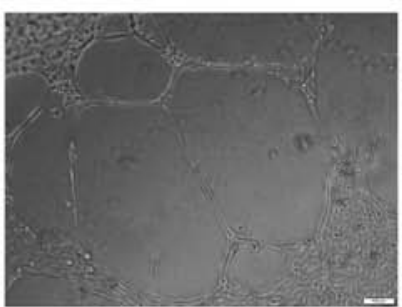

$\mathrm{NC}$

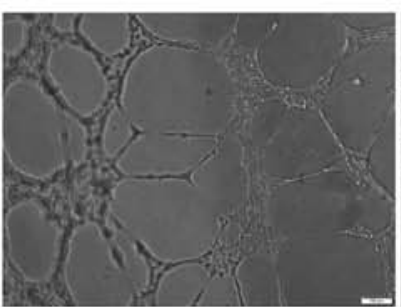

IN328

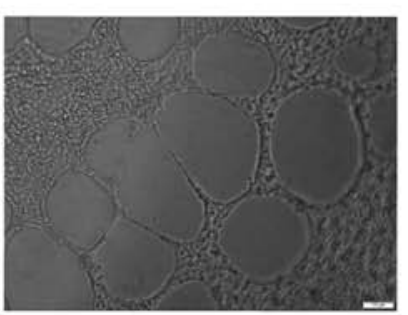

IN $328+$ Perifosine

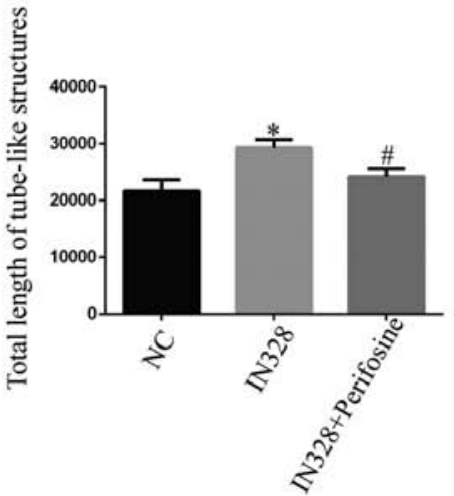

B
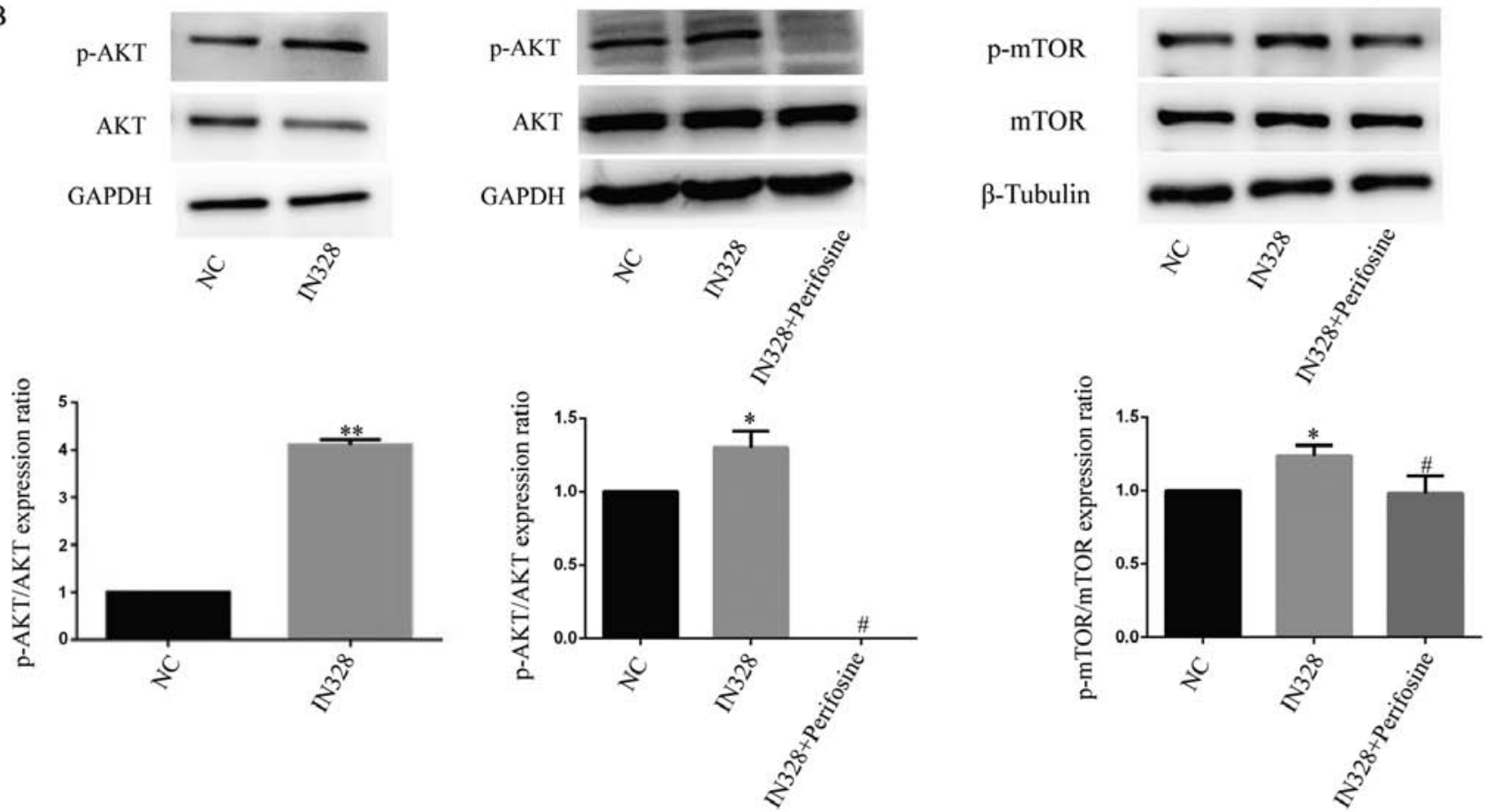

Figure 4. Downregulation of miR-328 activates the AKT/mTOR signaling pathway under HG and low serum conditions. By inhibiting the phosphorylation of AKT, the AKT-mTOR signaling pathway was inhibited and IN328-mediated angiogenesis was partially reversed. (A) The tube-like structure formation of HUVECs was detected using tube formation assays (magnification, x100). Scale bar, $200 \mu \mathrm{m}$. (B) Protein expression levels were determined by western blotting and the ratios of p-AKT/AKT and p-mTOR/mTOR were determined by western blotting, after miR-328 was downregulated and after both miR-328 downregulation and inhibition of the AKT pathway using perifosine. ${ }^{*} \mathrm{P}<0.05$ and ${ }^{* *} \mathrm{P}<0.01$ vs. NC; ${ }^{*} \mathrm{P}<0.05$ vs. IN328. miR, microRNA; HG, high glucose; IN328, miR328 inhibitor; p, phosphorylated; NC, negative control.

altered in response to $\mathrm{HG}$ and low serum conditions, as well as whether the alterations contributed to HUVEC angiogenesis damage under HG and low serum conditions were investigated. To the best of our knowledge, the present study was the first to investigate the role of miR-328 in HUVECs under HG and low serum conditions. The aim of the present study was to preliminary explore the role of miR-328 in diabetes-related vascular complications; therefore, high glucose combined with low serum conditions were used to establish a cell model that directly simulated the state of vascular endothelial cells during diabetic limb ischemia (17). The results indicated that endothelial cell angiogenesis was inhibited under HG and low serum condition, which was consistent with the results reported by Caporali et al (1). It was also speculated whether either condition was sufficient to give rise to the effects observed in the present study. High-glucose can significantly decreased cell features such as angiogenic capability (23), however, further investigation is required. In the present study,
miR-328 expression levels were significantly upregulated in HUVECs under HG and low serum conditions compared with control HUVECs, which indicated that downregulation of miR-328 promoted HUVEC angiogenesis under HG and low serum conditions. Further experiments indicated that miR-328 mediated endothelial cell angiogenesis, at least in part, by regulating PIM1 and the AKT/mTOR signaling pathway.

Angiogenesis is primarily associated with endothelial cell migration, proliferation and tube-like structure formation, which can be regulated by miRNAs (24). In the wound healing assay, serum-free conditions alter cell proliferation and migration; therefore, to observe the effects of $\mathrm{HG}$ $+2 \%$ FBS on cell migration, the control group was cultured with $2 \%$ FBS; the use of $2 \%$ FBS during the wound healing assay was a limitation of the study. It has been reported that miR-328 is related to DM and can regulate the proliferation and migration of tumor cells $(14,25)$. The majority of studies on miR-328 have focused on tumors and cardiovascular 
A

\begin{tabular}{|c|c|}
\hline & $\begin{array}{l}\text { Predicted consequential pairing of target region (top) } \\
\text { and miRNA (bottom) }\end{array}$ \\
\hline Position 602-609 of & 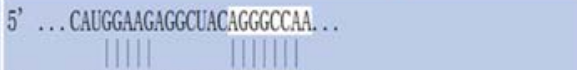 \\
\hline hsa-miR-328-3p & 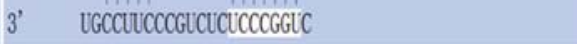 \\
\hline
\end{tabular}
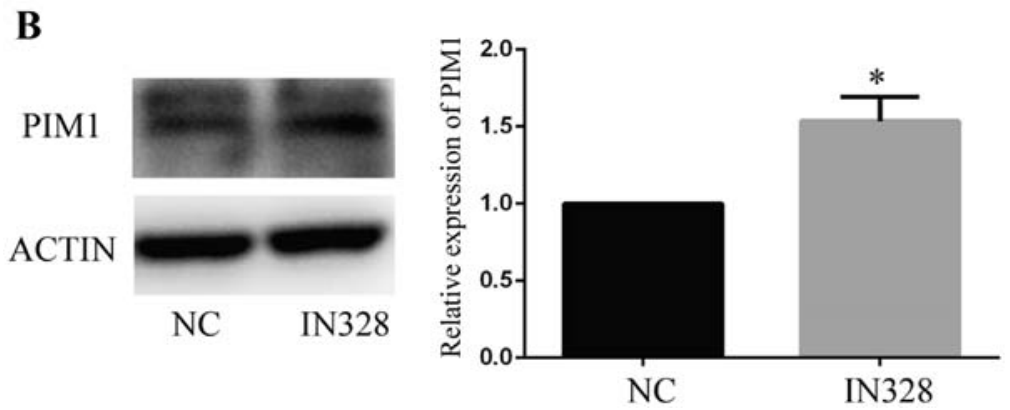

Figure 5. PIM1 may be a potential target of miR-328. (A) miRWalk2.0 database was used to predict consequential pairing of the target region and miR-328 (B) PIM1 protein expression levels were determined by western blotting and semi-quantified. "P $<0.05$ vs. NC. PIM1, pim-1 proto-oncogene, serine/threonine kinase; miR, microRNA; NC, negative control; 3'UTR, 3' untranslated region; IN328, miR-328 inhibitor.

\section{Endothelial cells}

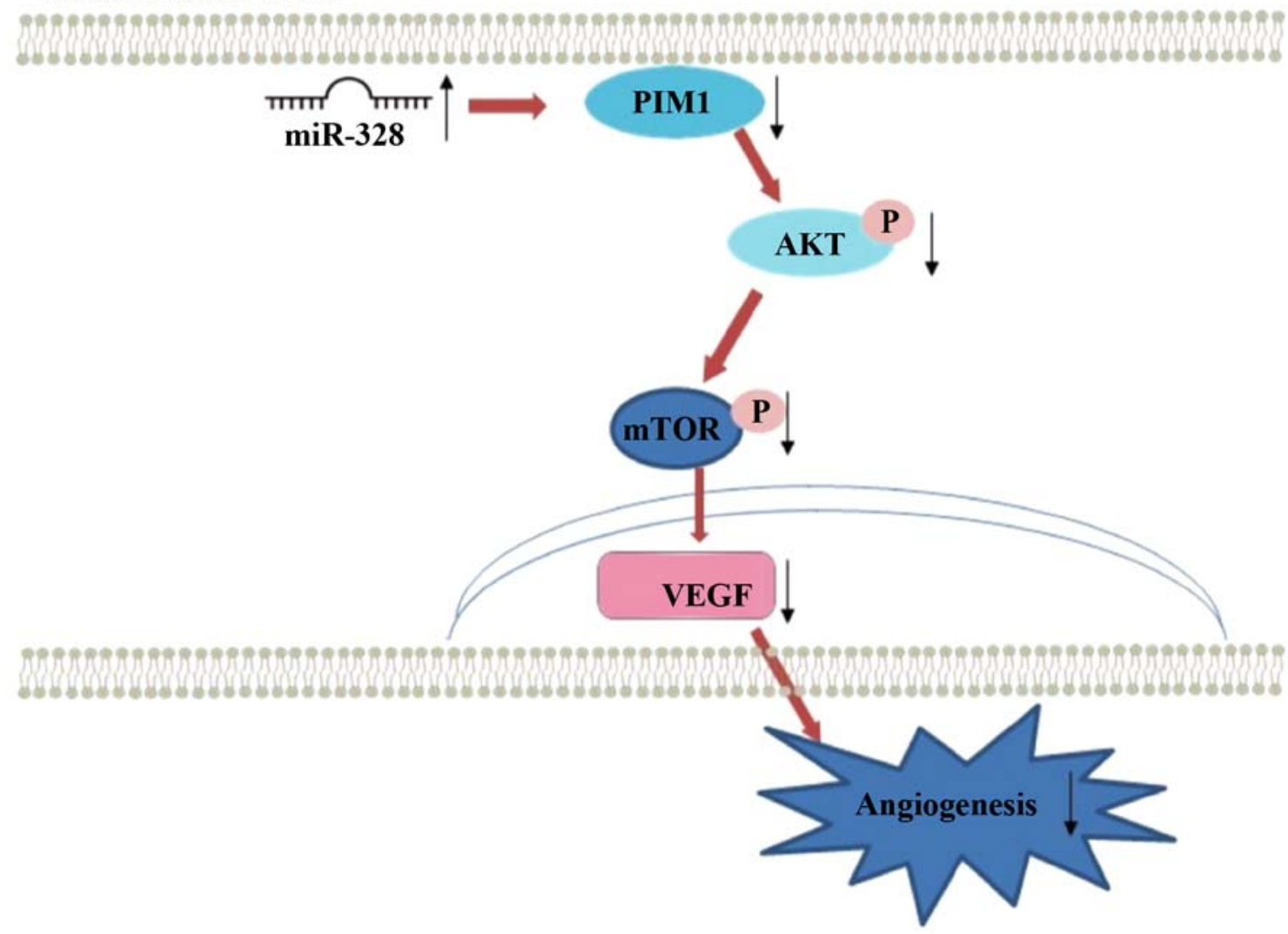

Figure 6. Proposed signaling pathway that inhibits endothelial cell angiogenesis under high glucose and low serum conditions. miR, microRNA; PIM1, pim-1 proto-oncogene, serine/threonine kinase; p, phosphorylated; VEGF, vascular endothelial growth factor.

diseases. It has been reported that the expression of miR-328 is decreased in esophageal, liver and colon cancer, where it can inhibit the proliferation, migration and survival of cancer cells (26-28). In cardiovascular diseases, miR-328 is associated with endothelial cell mesenchymal transformation, atrial fibrillation and myocardial fibrosis (13,29-31); therefore, it was hypothesized that miR-328 may regulate endothelial cell function and thus, affect angiogenesis (13,26-28). Firstly, the effect of HG and low serum conditions on endothelial cell function was investigated, which indicated that the conditions inhibited cell migration and tube-like structure formation, and promoted cytotoxicity. Subsequently, similar to its function in tumor cells and pulmonary arterial smooth muscle cells (25), the results of the present study further 
indicated that miR-328 expression levels were upregulated under HG and low serum conditions compared with the control group. Among the endothelial cell survival-related signaling pathways, ERK, JNK and AKT were investigated, and the results suggested that only AKT protein expression levels were decreased under HG and low serum conditions compared with the control group, which suggested that AKT signaling was involved.

Subsequently, the specific mechanism of action underlying miR-328-mediated regulation of endothelial cells and the signaling pathways involved were investigated. Following downregulation of miR-328, HG and low serum condition-mediated inhibitory effects on cell survival, including migration and tube-like structure formation, were reversed, which indicated that miR-328 regulated cell angiogenesis. In addition, downregulation of miR-328 promoted AKT activation, which suggested that miR-328 mediated AKT-regulated angiogenesis in DM-associated endothelial dysfunction. Furthermore, inhibition of AKT using the AKT specific inhibitor periosine partially reduced IN328-mediated stimulation of angiogenesis.

AKT, a protein kinase $\mathrm{B}$, is a serine/threonine-specific protein kinase, which serves a key role in cell proliferation-related processes, such as glucose metabolism, cell cycle regulation, angiogenesis and cell invasion (32). Previous studies have demonstrated that AKT is an effective angiogenesis factor (33-35). Hu et al (36) and Fathi et al (37), reported that PIM1 inhibition inhibited AKT phosphorylation, indicating that AKT was downstream of PIM1. To further study the downstream effects of the AKT signaling pathway, the angiogenesis-related mTOR signaling pathway was screened for validation. The results further indicated that mTOR was a downstream signal of AKT. Similar to the results reported by Chen et al (38), it has also been hypothesized that the AKT/mTOR signaling pathway regulates cell proliferation and angiogenesis by inducing the expression of hypoxia-inducible factor $1 \alpha$ and VEGF (39). Therefore, miR-328-mediated AKT/mTOR signaling may be associated with HUVEC angiogenesis.

miRNAs can guide ribosome binding to the 3'-untranslated region of target genes and post-transcriptionally inhibit target gene translation (40); therefore, the function of miR-328 depends on the target molecule. Bioinformatics analysis predicted that PIM1 may be a target gene of miR-328. The results indicated that PIM1 protein expression levels were regulated by miR-328 and that PIM1 may be a target of miR-328. However, further investigation is required to confirm that PIM1 is a target gene of miR-328. PIM1 is a serine/threonine kinase that has diverse biological roles in cell survival, proliferation and differentiation (41). The PIM family of proteins, a family of proto-oncogenes, display increased expression levels in a variety of malignancies. PIM kinases enhance cell survival and suppress apoptosis in multiple types of tumor cells $(36,37,42)$. Previous studies have also indicated that PIM1 can promote endothelial migration and angiogenesis, and inhibit cytotoxicity $(21,43,44)$. The results of the present study demonstrated that miR-328 altered endothelial cell angiogenesis, at least in part, by interacting with PIM1. Further studies are required to investigate the direct or indirect relationship between miR-328 and PIM1. Moreover, alterations to endothelial cell angiogenesis, including cell migration, cytotoxicity and tube formation, and the AKT signaling pathway following PIM1 gene regulation need to be investigated in future studies. Based on the results of the present study and the aforementioned previous studies, it could be suggested that the mechanism underlying endothelial cell angiogenesis inhibition under HG and low serum conditions involves increasing the expression of miR-328, which negatively regulates PIM1 and subsequently, inhibits the AKT/mTOR signaling pathway to inhibit angiogenesis.

In conclusion, the present study demonstrated that $\mathrm{HG}$ and low serum conditions inhibited endothelial cell angiogenesis and increased the expression of miR-328 in HUVECs. Moreover, downregulation of miR-328 in HUVECs under HG and low serum condition promoted endothelial cell angiogenesis. The mechanism of action underlying miR-328-mediated regulation of endothelial cell angiogenesis under $\mathrm{HG}$ and low serum conditions may be via the PIM1 and AKT/mTOR signaling pathway. The results of the present study may provide novel therapeutic targets for diabetic vascular complications.

\section{Acknowledgements}

Not applicable.

\section{Funding}

The present study was supported by the Education Department of Sichuan Province (grant nos. 16ZA0179 and 14TD0018) and the Joint Project of Luzhou City and Southwest Medical University (grant no. 2017LZXNYD-J18).

\section{Availability of data and materials}

All datasets used and/or analyzed during the current study are available from the corresponding author on reasonable request.

\section{Authors' contributions}

YZ and XZ conceived and designed the study. YZ, FW, QL and XD performed the cell culture, RT-qPCR and cell function experiments, and interpreted the data. $\mathrm{RH}$ and $\mathrm{XH}$ performed the western blotting experiments and interpreted the data. YZ wrote the manuscript. All authors read and approved the final manuscript and agree to be accountable for all aspects of the research in ensuring that the accuracy or integrity of any part of the work are appropriately investigated and resolved.

\section{Ethics approval and consent to participate}

Not applicable.

\section{Patient consent for publication}

Not applicable.

\section{Competing interests}

The authors declare that they have no competing interests. 


\section{References}

1. Caporali A, Meloni M, Nailor A, Mitić T, Shantikumar S Riu F, Sala-Newby GB, Rose L, Besnier M, Katare R, et al: p75(NTR)-dependent activation of NF- $\varkappa$ B regulates microRNA-503 transcription and pericyte-endothelial crosstalk in diabetes after limb ischaemia. Nat Commun 6: 8024, 2015.

2. Lunder M, Janić M and Šabovič M: Prevention of vascular complications in diabetes mellitus patients: Focus on the arterial wall. Curr Vasc Pharmacol 17: 6-15, 2019.

3. Barshes NR and Grant CL: Advances in the management of peripheral artery disease. Curr Diab Rep 19: 36, 2019.

4. Dal Canto E, Ceriello A, Rydén L,Ferrini M,Hansen TB, Schnell O, Standl E and Beulens JW: Diabetes as a cardiovascular risk factor: An overview of global trends of macro and micro vascular complications. Eur J Prev Cardiol 26 (2_suppl): 25-32, 2019.

5. He S, Zhao T, Guo H, Meng Y, Qin G, Goukassian DA, Han J, Gao X and Zhu Y: Coordinated activation of VEGF/VEGFR-2 and PPAR $\delta$ pathways by a multi-component Chinese medicine DHI accelerated recovery from peripheral arterial disease in type 2 diabetic mice. PLoS One 11: e0167305, 2016.

6. Nazer B, Ghahghaie F, Kashima R, Khokhlova T, Perez C, Crum L, Matula T and Hata A: Therapeutic ultrasound promotes reperfusion and angiogenesis in a rat model of peripheral arterial disease. Circ J 79: 2043-2049, 2015.

7. Zhu Y, Wang Y, Jia Y, Xu J and Chai Y: Roxadustat promotes angiogenesis through HIF-1 $\alpha / \mathrm{VEGF} / \mathrm{VEGFR} 2$ signaling and accelerates cutaneous wound healing in diabetic rats. Wound Repair Regen 27: 324-334, 2019.

8. Lazarovici P, Lahiani A, Gincberg G, Haham D, Fluksman A, Benny O, Marcinkiewicz C and Lelkes PI: Nerve growth factor-induced angiogenesis: 1. Endothelial cell tube formation assay. Methods Mol Biol 1727: 239-250, 2018.

9. Can L, Junxiong Z, Bao H, Wen Z, Hong W, Huijie L, Yingsheng $X$ and Chunli S: Single intraosseous injection of simvastatin promotes endothelial progenitor cell mobilization, neovascularization, and wound healing in diabetic rats. Plast Reconstr Surg 145: 433-443, 2020

10. Odent Grigorescu G, Rosca AM, Preda MB, Tutuianu R, Simionescu M and Burlacu A: Synergic effects of VEGF-A and SDF-1 on the angiogenic properties of endothelial progenitor cells. J Tissue Eng Regen Med 11: 3241-3252, 2017.

11. Tiwari A, Mukherjee B and Dixit M: MicroRNA key to angiogenesis regulation: MiRNA biology and therapy. Curr Cancer Drug Targets 18: 266-277, 2018.

12. Gong M, Yu B, Wang J, Wang Y, Liu M, Paul C, Millard RW, Xiao DS, Ashraf M and Xu M: Mesenchymal stem cells release exosomes that transfer miRNAs to endothelial cells and promote angiogenesis. Oncotarget 8: 45200-45212, 2017.

13. Chen Y, Yang Q, Zhan Y, Ke J, Lv P and Huang J: The role of miR-328 in high glucose-induced endothelial-to-mesenchymal transition in human umbilical vein endothelial cells. Life Sci 207 110-116, 2018

14. Li DS, Feng L, Luo LH, Duan ZF, Li XL, Yin CH and Sun X: The Effect of microRNA-328 antagomir on erectile dysfunction in streptozotocin-induced diabetic rats. Biomed Pharmacother 92: 888-895, 2017.

15. Yi W, Tu MJ, Liu Z, Zhang C, Batra N, Yu AX and Yu AM: Bioengineered miR-328-3p modulates GLUT1-mediated glucose uptake and metabolism to exert synergistic antiproliferative effects with chemotherapeutics. Acta Pharm Sin B 10: 159-170, 2020.

16. Prado MSG, de Goes TC, de Jesus ML, Mendonça LSO, Nascimento JS and Kaneto CM: Identification of miR-328-3p as an endogenous reference gene for the normalization of miRNA expression data from patients with Diabetic Retinopathy. Sci Rep 9: 19677, 2019.

17. Caporali A, Meloni M, Völlenkle C, Bonci D, Sala-Newby GB, Addis R,Spinetti G,LosaS,MassonR,Baker AH, etal:Deregulation of microRNA-503 contributes to diabetes mellitus-induced impairment of endothelial function and reparative angiogenesis after limb ischemia. Circulation 123: 282-291, 2011.

18. Ying C, Sui-Xin L, Kang-Ling X, Wen-Liang Z, Lei D, Yuan L, Fan Z and Chen Z: MicroRNA-492 reverses high glucose-induced insulin resistance in HUVEC cells through targeting resistin. Mol Cell Biochem 391: 117-125, 2014

19. Wang M, Li W, Chang GQ, Ye CS, Ou JS, Li XX, Liu Y, Cheang TY, Huang XL and Wang SM: MicroRNA-21 regulates vascular smooth muscle cell function via targeting tropomyosin 1 in arteriosclerosis obliterans of lower extremities. Arterioscler Thromb Vasc Biol 31: 2044-2053, 2011.
20. Livak KJ and Schmittgen TD: Analysis of relative gene expression data using real-time quantitative PCR and the 2(- $\Delta \Delta \mathrm{C}(\mathrm{T}))$ Method. Methods 25: 402-408, 2001.

21. Chen M, Yi B, Zhu N, Wei X, Zhang GX, Huang S and Sun J: Pim1 kinase promotes angiogenesis through phosphorylation of endothelial nitric oxide synthase at Ser-633. Cardiovasc Res 109: 141-150, 2016.

22. Durak-Kozica M, Paszek E and Stepień EŁ: Role of the Wnt signalling pathway in the development of endothelial disorders in response to hyperglycaemia. Expert Rev Mol Med 21: e7, 2019.

23. Schiano C, Grimaldi V, Franzese M, Fiorito C, De Nigris F, DonatelliF, Soricelli A,Salvatore Mand Napoli C:Non-nutritional sweeteners effects on endothelial vascular function. Toxicol In Vitro 62: 104694, 2020.

24. Wang J, Yang L, Liang F, Chen Y and Yang G: Integrin alpha $\mathrm{x}$ stimulates cancer angiogenesis through PI3K/Akt signaling-mediated VEGFR2/VEGF-A overexpression in blood vessel endothelial cells. J Cell Biochem 120: 1807-1818, 2019.

25. Qian Z, Zhang L, Chen J, Li Y, Kang K, Qu J, Wang Z, Zhai Y, Li L and Gou D: MiR-328 targeting PIM-1 inhibits proliferation and migration of pulmonary arterial smooth muscle cells in PDGFBB signaling pathway. Oncotarget 7: 54998-55011, 2016.

26. Han N, Zhao W, Zhang Z and Zheng P: MiR-328 suppresses the survival of esophageal cancer cells by targeting PLCE1. Biochem Biophys Res Commun 470: 175-180, 2016.

27. Zhang X, Xin G and Sun D: Serum exosomal miR-328, miR-575, miR-134 and miR-671-5p as potential biomarkers for the diagnosis of Kawasaki disease and the prediction of therapeutic outcomes of intravenous immunoglobulin therapy. Exp Ther Med 16: 2420-2432, 2018

28. Li Y, Duo Y, Zhai P, He L, Zhong K, Zhang Y, Huang K, Luo J, Zhang $\mathrm{H}$ and $\mathrm{Yu} \mathrm{X}$ : Dual targeting delivery of miR-328 by functionalized mesoporous silica nanoparticles for colorectal cancer therapy. Nanomedicine (Lond) 13: 1743-5889, 2018.

29. Zhao D, Li C, Yan H, Li T, Qian M, Zheng N, Jiang H, Liu L, $\mathrm{Xu} \mathrm{B}, \mathrm{Wu} \mathrm{Q}$, et al: Cardiomyocyte derived mir-328 promotes cardiac fibrosis by paracrinely regulating adjacent fibroblasts. Cell Physiol Biochem 46: 1555-1565, 2018.

30. Soeki T, Matsuura T, Bando S, Tobiume T, Uematsu E, Ise T, Kusunose K, Yamaguchi K, Yagi S, Fukuda D, et al: Relationship between local production of microRNA-328 and atrial substrate remodeling in atrial fibrillation. J Cardiol 68: 472-477, 2016.

31. He F, Lv P, Zhao X, Wang X, Ma X, Meng W, Meng X and Dong S: Predictive value of circulating miR-328 and miR-134 for acute myocardial infarction. Mol Cell Biochem 394: 137-144, 2014.

32. Yan X, Hui Y, Hua Y, Huang L, Wang L, Peng F, Tang C, Liu D, Song J and Wang F: EG-VEGF silencing inhibits cell proliferation and promotes cell apoptosis in pancreatic carcinoma via PI3K/AKT/mTOR signaling pathway. Biomed Pharmacother 109: 762-769, 2019.

33. Di Y and Chen XL: Inhibition of LY294002 in retinal neovascularization via down-regulation the PI3K/AKT-VEGF pathway in vivo and in vitro. Int J Ophthalmol 11: 1284-1289, 2018.

34. Chen J, Li F, Xu Y, Zhang W, Hu Y, Fu Y, Xu W, Ge S, Fan X and Lu L: Cholesterol modification of SDF-1-specific siRNA enables therapeutic targeting of angiogenesis through Akt pathway inhibition. Exp Eye Res 184: 64-71, 2019.

35. Wu J,ZhaoX, SunQ, Jiang Y,Zhang W,LuoJ and Li Y: Synergic effect of PD-1 blockade and endostar on the PI3K/AKT/mTOR-mediated autophagy and angiogenesis in Lewis lung carcinoma mouse model. Biomed Pharmacother 125: 109746, 2020.

36. Hu XF, Li J, Vandervalk S, Wang Z, Magnuson NS and Xing PX: PIM-1-specific $\mathrm{mAb}$ suppresses human and mouse tumor growth by decreasing PIM-1 levels, reducing Akt phosphorylation, and activating apoptosis. J Clin Invest 119: 362-375, 2009

37. Fathi AT, Arowojolu O, Swinnen I, Sato T, Rajkhowa T, Small D, Marmsater F, Robinson JE, Gross SD, Martinson M, et al: A potential therapeutic target for FLT3-ITD AML: PIM1 kinase. Leuk Res 36: 224-231, 2012.

38. Chen QY, Jiao DM, Wu YQ, Chen J, Wang J, Tang XL, Mou H, Hu HZ, Song J, Yan J, et al: MiR-206 inhibits HGF-induced epithelial-mesenchymal transition and angiogenesis in non-small cell lung cancer via c-Met /PI3k/Akt/mTOR pathway. Oncotarget 7: 18247-18261, 2016.

39. Zhang Y, Cheng H, Li W, Wu H and Yang Y: Highly-expressed $\mathrm{P} 2 \mathrm{X} 7$ receptor promotes growth and metastasis of human HOS/MNNG osteosarcoma cells via PI3K/Akt/GSK3 $\beta / \beta$-catenin and mTOR/HIF1 $\alpha /$ VEGF signaling. Int J Cancer 145: 1068-1082, 2019.

40. Baigude $\mathrm{H}$ and Rana TM: Strategies to antagonize miRNA functions in vitro and in vivo. Nanomediwcine (Lond) 9: 2545-2555, 2014 
41. Zhang F, Beharry ZM, Harris TE, Lilly MB, Smith CD Mahajan S and Kraft AS: PIM1 protein kinase regulates PRAS40 phosphorylation and mTOR activity in FDCP1 cells. Cancer Biol Ther 8: 846-853, 2009.

42. Leung CO, Wong CC, Fan DN, Kai AK, Tung EK, Xu IM, Ng IO and Lo RC: PIM1 regulates glycolysis and promotes tumor progression in hepatocellular carcinoma. Oncotarget 6: 10880-10892, 2015.

43. Walpen T, Kalus I, Schwaller J, Peier MA, Battegay EJ and Humar R: Nuclear PIM1 confers resistance to rapamycin-impaired endothelial proliferation. Biochem Biophys Res Commun 429: 24-30, 2012 .
44. Walpen T, Peier M, Haas E, Kalus I, Schwaller J, Battegay E and Humar R: Loss of pim1 imposes a hyperadhesive phenotype on endothelial cells. Cell Physiol Biochem 30: 1083-1096, 2012.

cc) (i) $(9$ This work is licensed under a Creative Commons Attribution-NonCommercial-NoDerivatives 4.0 International (CC BY-NC-ND 4.0) License. 